\title{
C2 and Greater Occipital Nerve: The Anatomic and Functional Implications in Spinal Surgery
}

\author{
M. Burhan Janjua ${ }^{1}$, Peter L. Zhou ${ }^{2}$, Jeffrey P. Greenfield ${ }^{3}$, Ali A. Baaj ${ }^{3}$, Anthony Frempong-
} Boadu $^{4}$

1. Neurosurgery, NYU Langone Medical Center, New York, NYC, USA 2. Hospital for Joint Diseases, New York University Langone Medical Center 3. Neurological Surgery, New York-Presbyterian/Weill Cornell Medical College 4. Neurosurgery/Spine Surgery, New York University Langone Medical Center

$\square$ Corresponding author: M. Burhan Janjua, mburhanj@gmail.com

Disclosures can be found in Additional Information at the end of the article

\section{Abstract}

\section{Introduction}

Posterior C1-C2 fusion is a highly successful treatment for atlantoaxial instability and other pathologies of the cervical spine, with fusion rates approaching 95\%-100\%. However, poor visualization of the lateral masses of $\mathrm{C} 1$ secondary to the course of the $\mathrm{C} 2$ nerve root along with blood loss from the venous plexus and compression of the $\mathrm{C} 2$ nerve from lateral mass screws are technical obstacles that can arise during surgery. Thus, sacrifice of the C2 nerve root has long since been debated in fusions involving the $\mathrm{C} 1$ and $\mathrm{C} 2$ vertebral bodies.

\section{Methods}

Cadaveric dissections on four adult specimens were performed. Both intradural and extradural courses of $\mathrm{C} 2$ were studied in detail. The tentative site of $\mathrm{C} 2$ nerve root compression during placement of $\mathrm{C} 1$ lateral mass screws was studied in detail. Both the indication as well as the ease of $\mathrm{C} 2$ neurectomy were studied in relation to postoperative compression and entrapment.

\section{Results}

Four-six dorsal rootlets of C2 nerve were observed while studying the intradural course. The extradural course was studied with respect to the lateral mass of $\mathrm{C} 1$. The greater occipital nerve (GON) course was fairly consistent in all specimens. Transection of C2 around its ganglion would allow for proper C1 lateral mass screw placement as the course of C2 nerve interferes with proper placement of instrumentation.

Received 02/08/2017

Review began 02/15/2017 Review ended 03/03/2017 Published 03/03/2017

C) Copyright 2017

Janjua et al. This is an open access article distributed under the terms of the Creative Commons Attribution License CC-BY 3.0., which permits unrestricted use, distribution, and reproduction in any medium, provided the original author and source are credited.

\section{Conclusion}

C2 nerve root transection is associated with occipital numbness but this often has no effect on health-related quality of life (HRQOL). The C2 nerve root preservation is often associated with entrapment neuropathy or occipital neuralgia, which greatly affects HRQOL. The C2 nerve root transection helps in better visualization, aids in optimal placement of C1 lateral mass screws, minimizes estimated blood loss and improves surgical outcome with successful fusion.

Categories: Neurosurgery, Orthopedics

Keywords: c2 neurectomy, occipital neuralgia, lateral mass screws, greater occipital nerve, c1-c2, c1-c2 


\section{Introduction}

Posterior C1-C2 (atlantoaxial) instrumentation and fusion are a surgical procedure employed to treat pathologies of axial cervical spine. There are various etiologies, which include degenerative and metabolic bone or ligamentous abnormalities, infectious or inflammatory joint diseases, congenital anomalies (os odontoideum and odontoid agenesis), trauma with destabilizing fractures, tumor, and iatrogenic causes from previous decompression surgeries. Atlantoaxial instability (AAI) can be asymptomatic in its mildest form, however, when symptomatic warrants C1-C2 fixation.

C1-C2 instrumented fusion can provide a reasonable relief from symptoms but it comes at the expense of loss of some rotational mobility of the cervical spine. Usually, surgery is limited by the complicated anatomy and the intricate course of the neurovascular structures in narrow and confined spaces. Multiple surgical techniques have evolved over the last 70 years to address AAI. In 1979, Magerl and Jeanneret described transarticular screw fixation. Later on, Goel's technique using $\mathrm{C} 1$ lateral mass screws and $\mathrm{C} 2$ pedicle screws with plates for posterior $\mathrm{C} 1-\mathrm{C} 2$ fusion has traditionally been considered a gold standard [1]. The technique was later revised by Harms, et al. by utilizing rods with C2 pars, and C1 lateral mass screw construct, now considered by many to be more feasible and favored technique [2]. As surgical advancements are made, the use of $\mathrm{C} 2$ nerve transection arose from cumbersome dissections, profuse bleeding from perivertebral venous plexus in the lateral gutters, anomalous course of neurovascular structures, poor visibility in decortication around the facet joint and foremost the deployment of $\mathrm{C} 1$ lateral mass screws.

The $\mathrm{C} 2$ nerve root occupies the dorsal aspect of the $\mathrm{C} 1-\mathrm{C} 2$ facet joint and obscures important landmarks for correct screw placement. Moreover, the implanted hardware can cause impingement or compression of the nerve root, which can lead to the development of neuropathic pain in the cutaneous distribution of C2 nerve (occipital neuralgia) [3-5]. Thus, preserving or sacrificing the nerve root has been a controversial issue where the decision is based on surgical experience and personal preference to enhance overall functional outcome.

This cadaveric study aims to delineate important anatomical landmarks for proper C1 screw placement and avoidance of postoperative occipital neuralgia. Furthermore, we aim to highlight the importance of anatomic landmarks of the posterior C1-C2 interspace while considering posterior instrumentation to minimize postoperative neuropathic pain when preserving $\mathrm{C} 2$. This study also details the microsurgical anatomy of the $\mathrm{C} 2$ nerve, its intradural and extradural course and the feasibility of either preserving or sacrificing $\mathrm{C} 2$ during posterior C1-C2 instrumentation and fusion.

\section{Materials And Methods}

Four formalin-fixed adult cadaveric specimens with well-preserved cervical spines up to the C4 spinous process were selected. Each specimen was placed in a three-point pin fixation device (Mayfield) in a prone position. The cervical spine was exposed from occiput to $\mathrm{C} 3$ in order to study the vital neuromuscular structures in the posterior C1-C2 disc space. Standard midline suboccipital approach was utilized for all specimens. In total, eight sides were dissected. The whole $\mathrm{C} 2$ nerve course starting from intradural dorsal rootlets to the extradural portion up to the terminal skin innervation of the vertex was studied bilaterally in all specimens. All microdissections of the $\mathrm{C} 1-\mathrm{C} 2$ disc space were performed under the surgical microscope. 


\section{Cureus}

A midline incision was performed up to the spinous process of C4. The skin and subcutaneous tissue were then carefully dissected. A meticulous subdermal dissection was carried out to expose the fascia of the trapezius muscle. Then, in a stepwise fashion, fascia was dissected to yield the opening of the greater occipital nerve (GON), a medial branch of the dorsal ramus of $\mathrm{C} 2$. The point of exit of the GON out of the aponeurosis of the trapezius muscle just lateral to the inion was observed in all specimens. This course was relatively consistent in all cadaveric specimens (Figure 1).

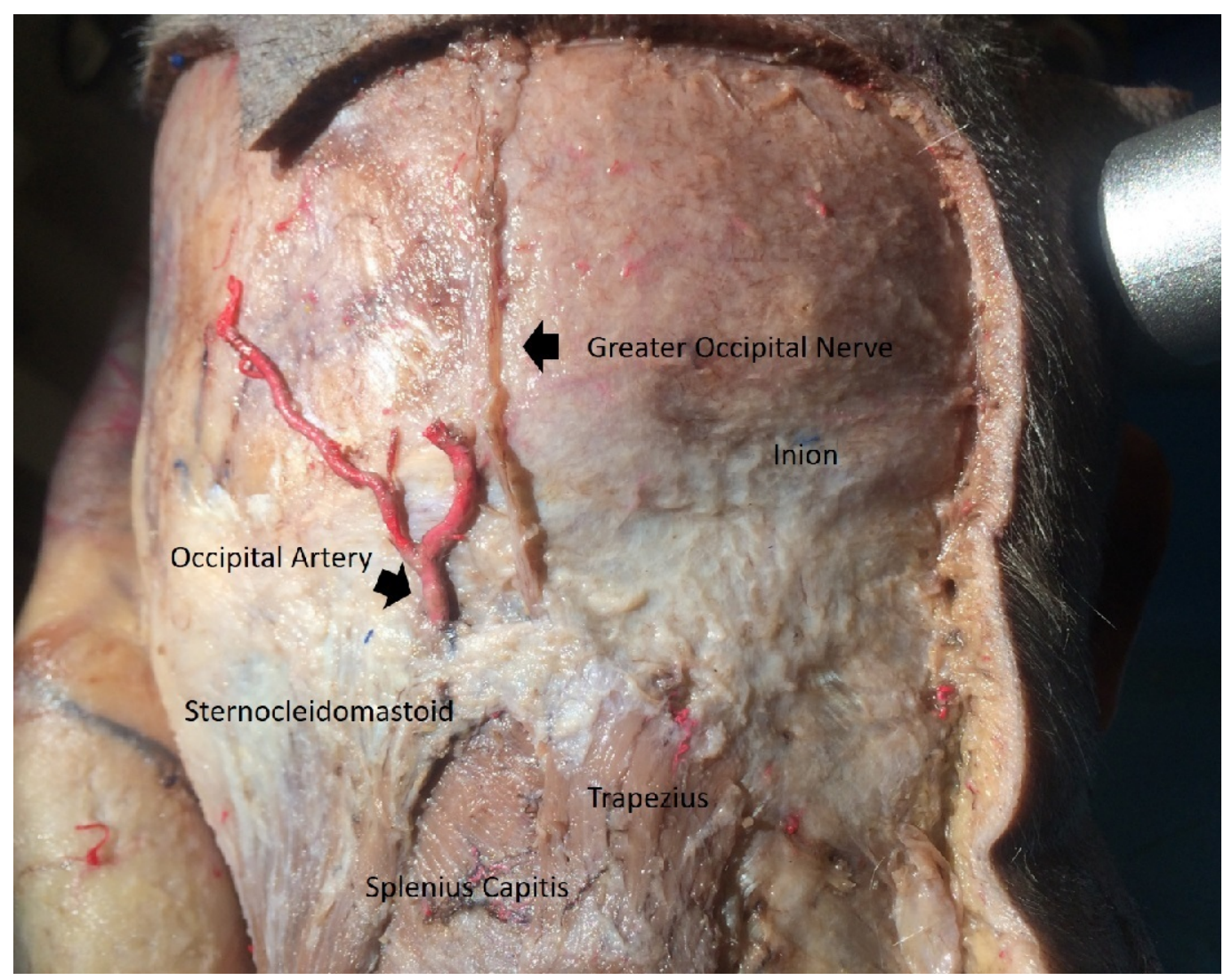

FIGURE 1: Suboccipital region depicting GON

During its course between trapezius and semispinalis capitis, the GON was noticed to receive a medial branch from C3. The skin incision was advanced further upwards to expose the terminal cutaneous innervation of $\mathrm{C} 2$ nerve up to the vertex (Figure 2). 


\section{Cureus}

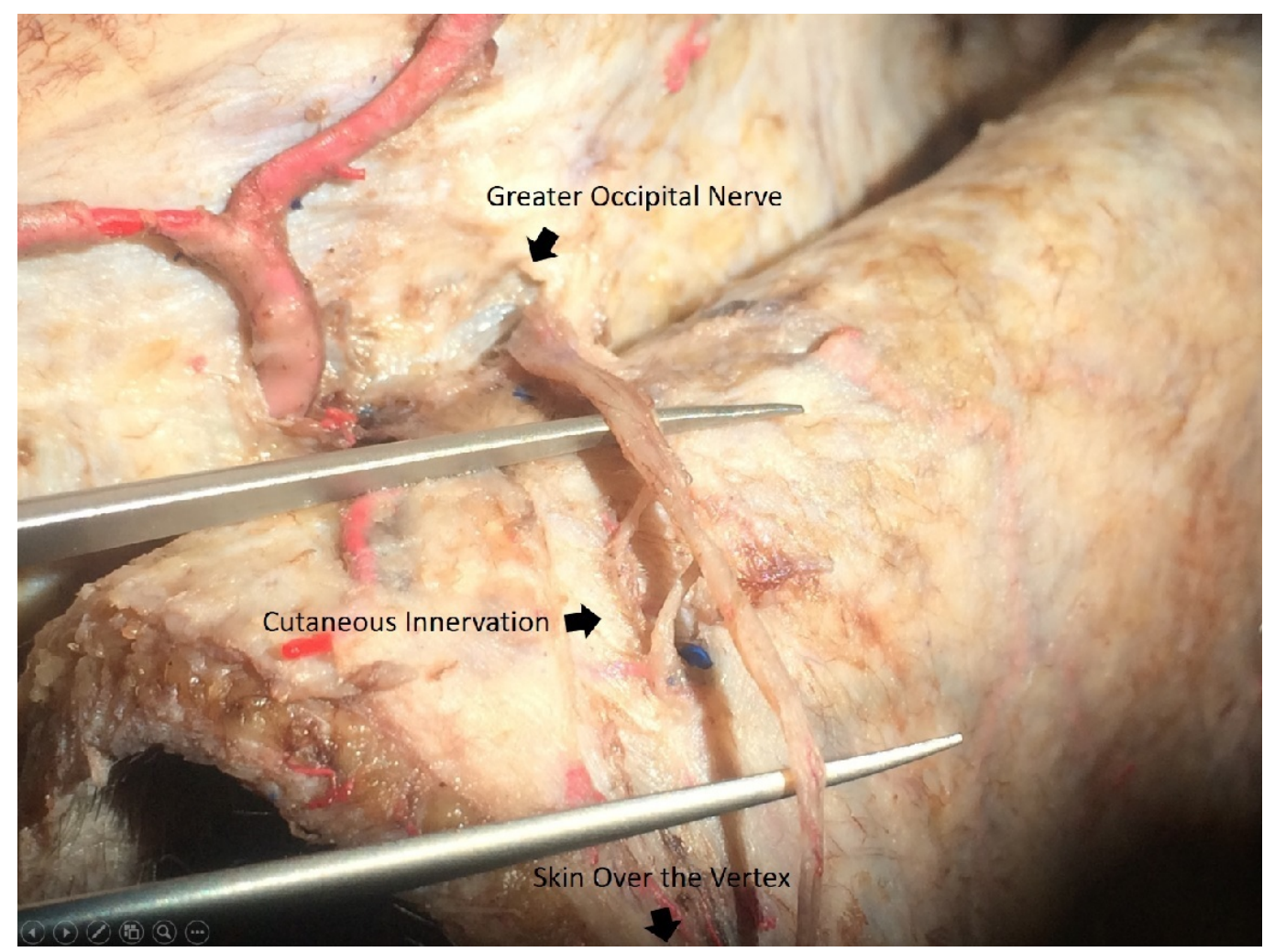

FIGURE 2: Cutaneous innervation over vertex

The course of GON after exiting after the fascia lateral to the inion

Then, the dissection was extended laterally to expose the fascia of the splenius capitis muscle. Afterward, the midline incision was extended subfascially through the trapezius muscle (Figure 3). 


\section{Cureus}

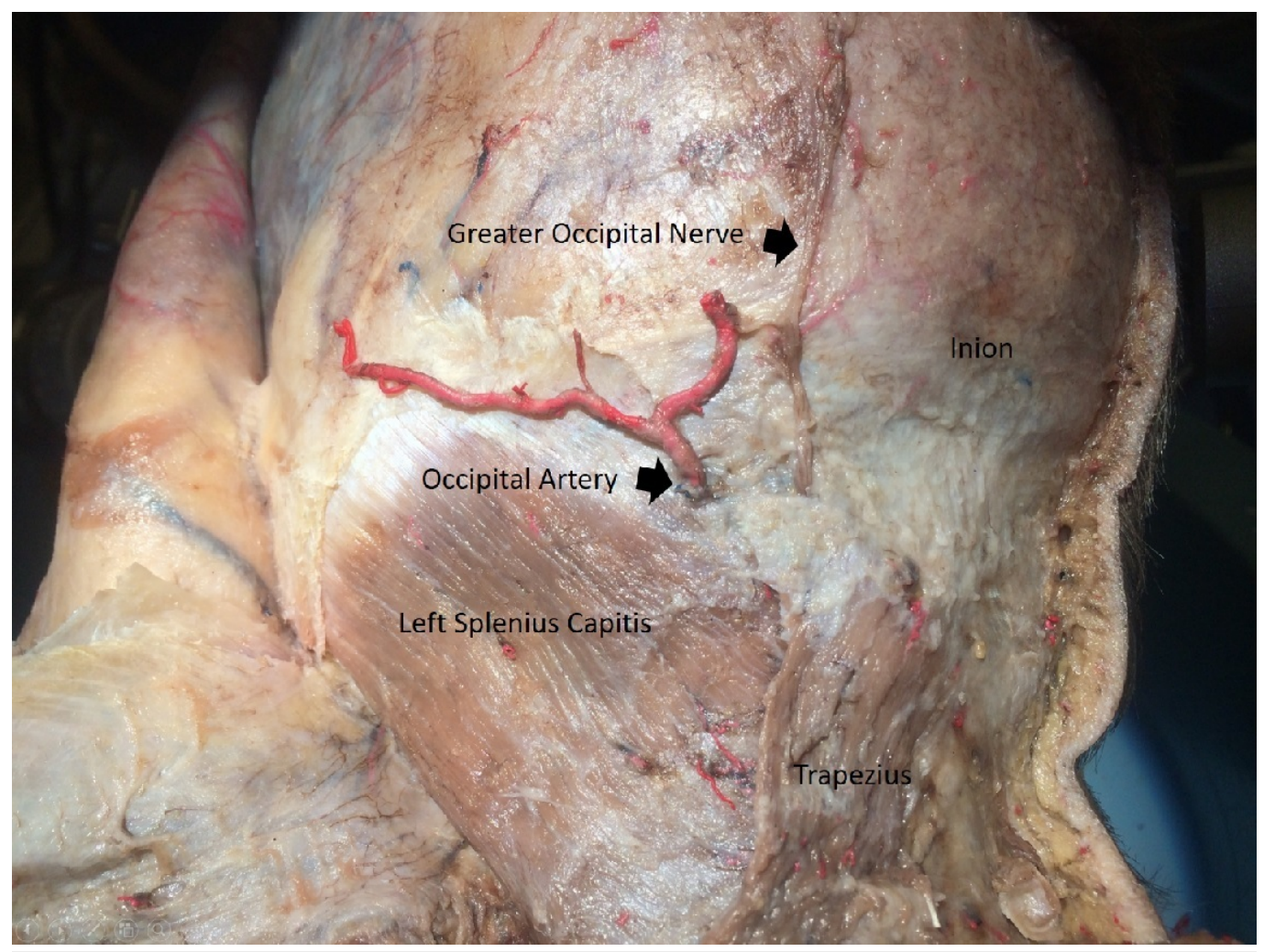

FIGURE 3: Trapezius split open to expose splenius capitis

Followed by a lateral retraction to expose the semispinalis capitis muscle (Figure 4). 


\section{Cureus}

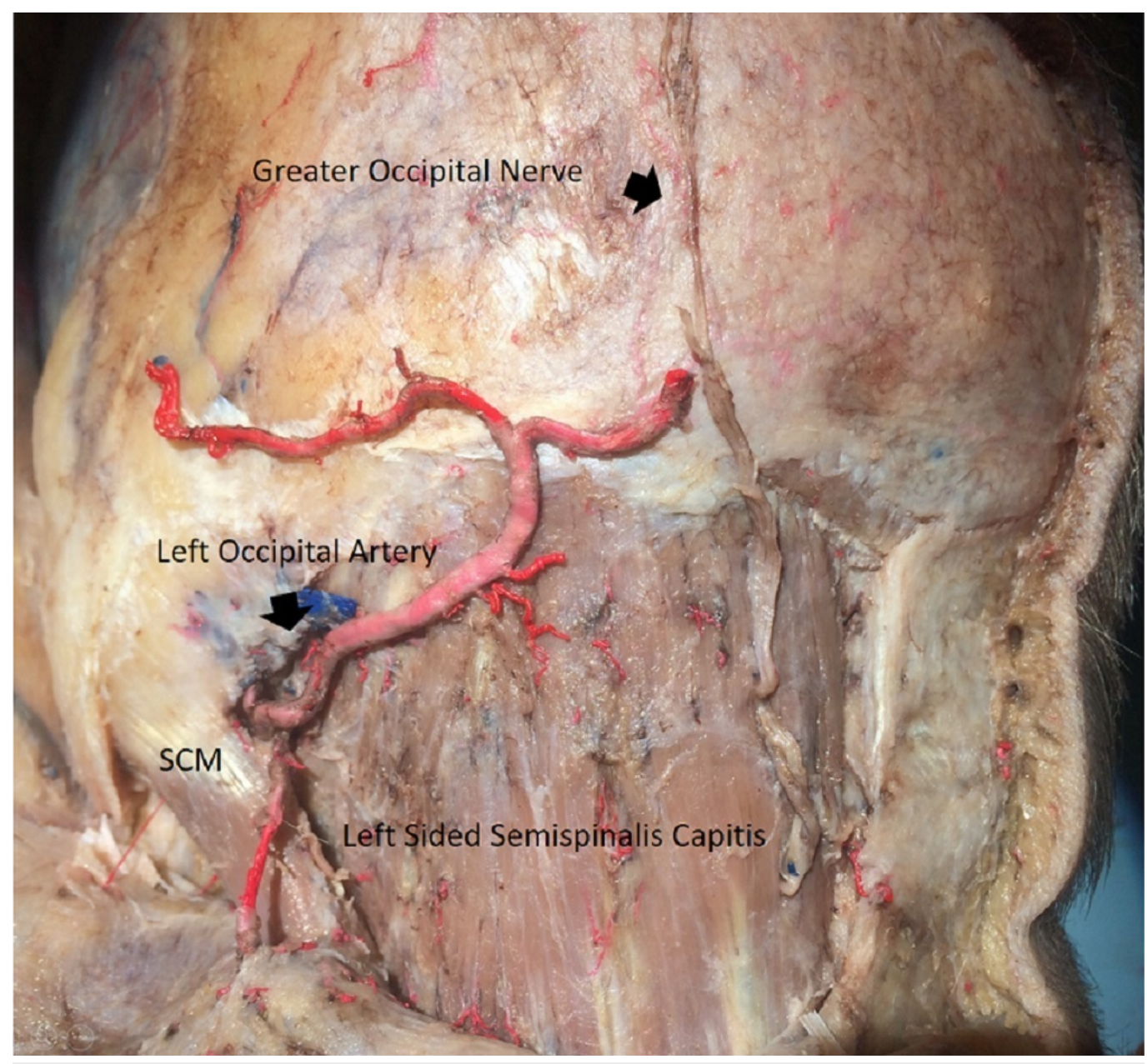

FIGURE 4: Splenius capitis dissected out

Splenius capitis was dissected out to expose the semispinalis capitis

The GON could be identified exiting the muscle (Figure 5), 


\section{Cureus}

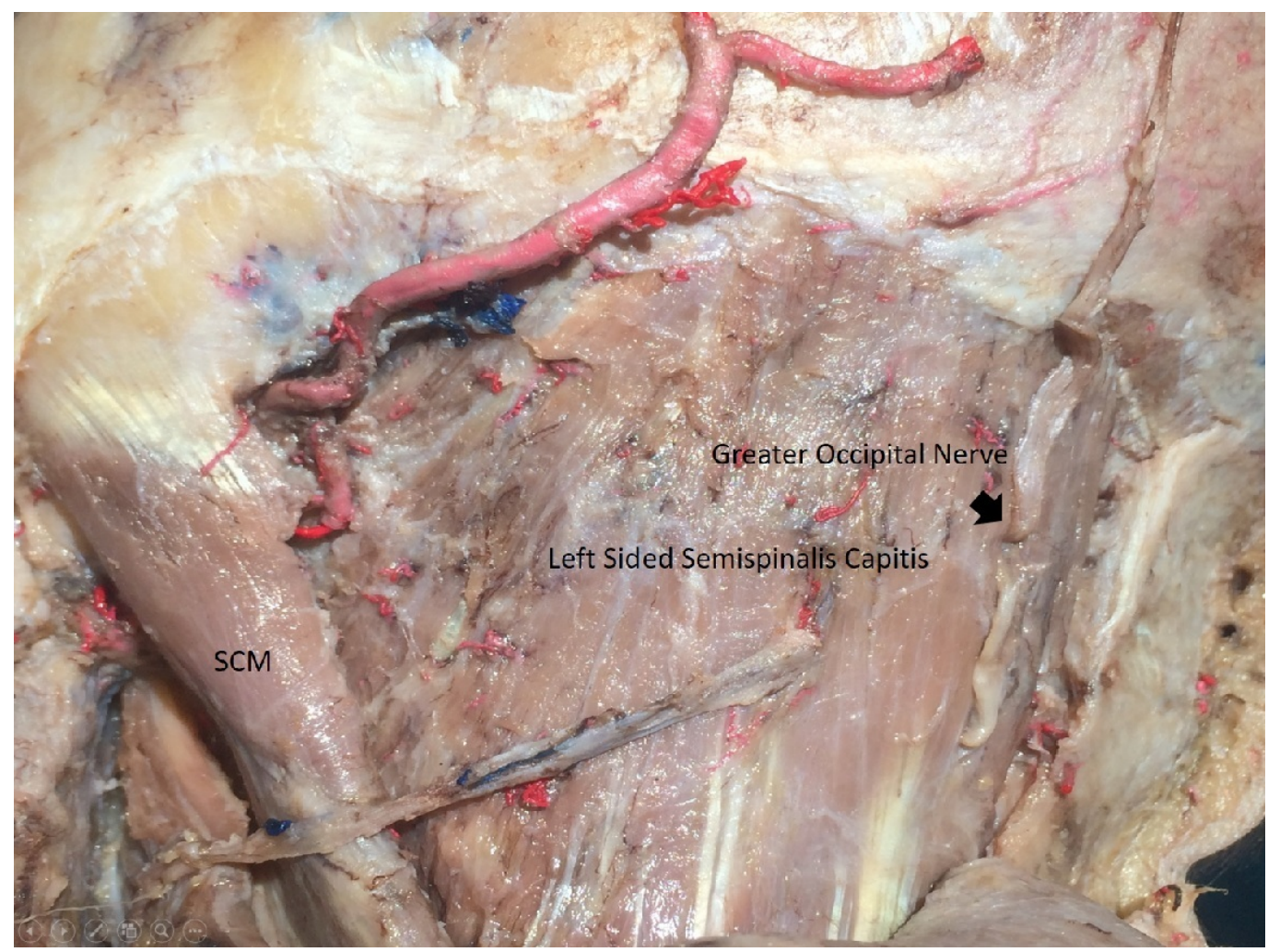

FIGURE 5: The GON exiting semispinalis capitis

and was then traced back to the inferior border of the inferior oblique muscle and to the posterior C1-C2 interspace (Figure 6).

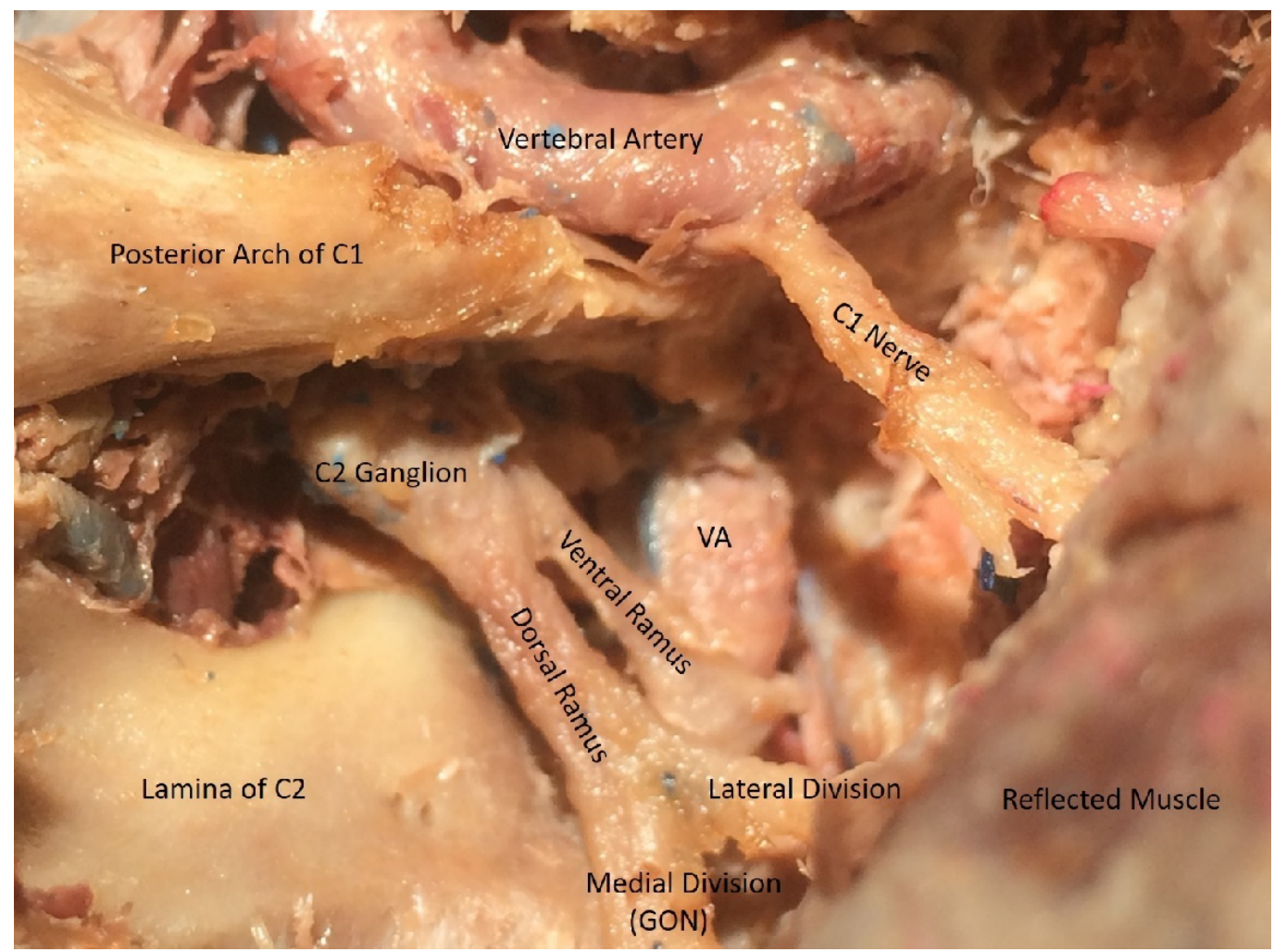

FIGURE 6: Posterior C1-C2 interspace 


\section{Cureus}

The dissection was then carried down to the $\mathrm{C} 2$ spinous process to expose the muscles attached to the spinous process. Subperiosteal dissection of the C2 nerves was carried out over the lamina bilaterally up to the C1-C2 facet joint (Figure 7).

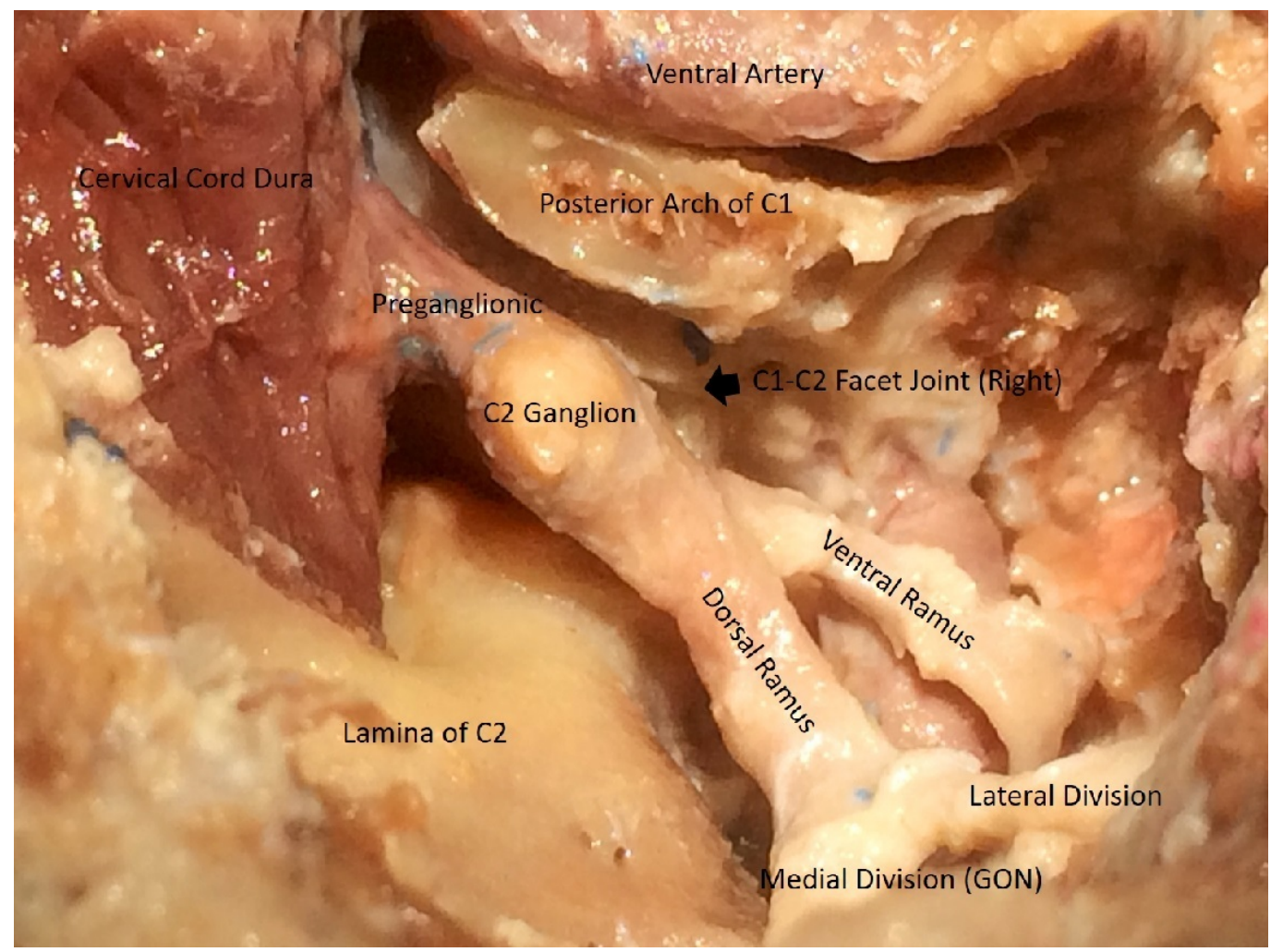

\section{FIGURE 7: Pre and post-ganglionic segments of $\mathrm{C} 2$ behind the facet joint}

A C1 laminectomy, utilizing a $4 \mathrm{~mm}$ cutting bar was subsequently performed to expose the spinal dura. The drilling was extended laterally while carefully preserving the vertebral artery running through the sulcus arteriosus. The vertebral artery was completely skeletonized up to the foramen transversarium. This led us to expose the $\mathrm{C} 1$ nerve root exiting under the vertebral artery. The $\mathrm{C} 1$ nerve, also known as the suboccipital nerve was observed leaving the vertebral canal between the occipital bone and the $\mathrm{C} 1$ vertebra. The dorsal ramus was found to be larger than the ventral ramus and coursed between the posterior arch of the $\mathrm{C} 1$ and the vertebral artery to reach the suboccipital triangle (formed by the rectus capitis posterior major, superior and inferior oblique muscles) (Figure 7). A durotomy was then performed utilizing size 15 blade in a standard fashion. The edges of the dura were cut laterally to expose the lateral extent of the cervical spinal cord. Four-six dorsal rootlets of $\mathrm{C} 2$ were identified exiting from the dorsal root entry zone of the dorsal segment of the spinal cord (Figure 8). Ventral rootlets were not dissected and limited by the suboccipital approach only. 


\section{Cureus}

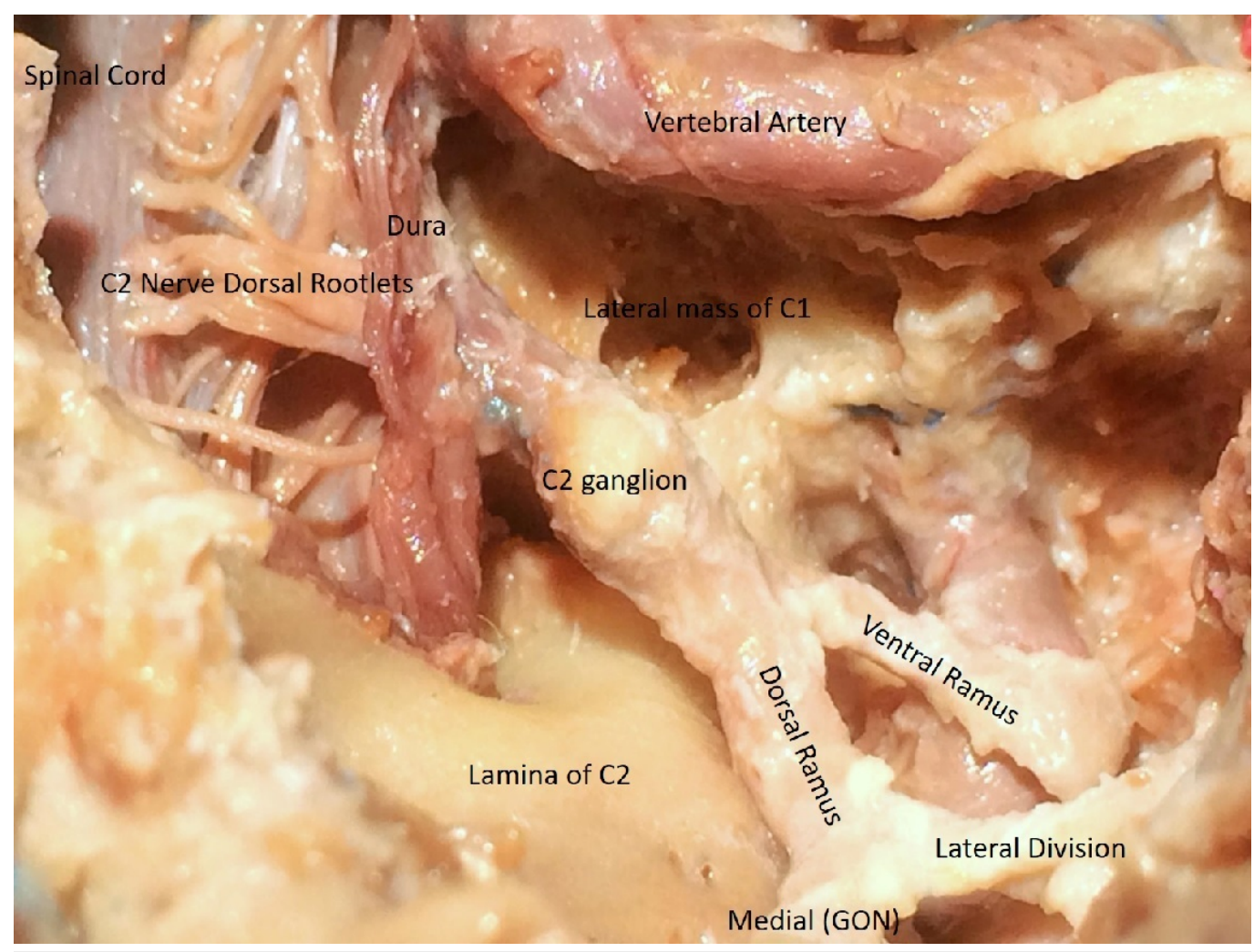

\section{FIGURE 8: Intra and extradural course of C2}

The extradural course of $\mathrm{C} 2$, along with its rami and divisions, in the posterior $\mathrm{C} 1-\mathrm{C} 2$ disc space

The $\mathrm{C} 2$ nerve root along with the $\mathrm{C} 2$ ganglion were identified. The number of $\mathrm{C} 2$ nerve rootlets, the proximal and distal location of $\mathrm{C} 2$ ganglion, its shape, and location relative to the posterior aspect of the lateral mass of $\mathrm{C} 1$ vertebra were closely observed (Figure 8).

\section{Results}

The GON and its course were fairly consistent in all specimens from inferior border of the inferior oblique muscle and up to the posterior $\mathrm{C} 1-\mathrm{C} 2$ disc space. However, the diameter of the preganglionic, ganglionic or postganglionic segments of $\mathrm{C} 2$ was found to be variable (not measured) in all specimens. After durotomy, four-six dorsal rootlets of $\mathrm{C} 2$ were observed in all specimens. The $\mathrm{C} 2$ nerve was observed to emerge from the spinal dura between the posterior arch of the $\mathrm{C} 1$ and the lamina of the $\mathrm{C} 2$ vertebra and continued as the $\mathrm{C} 2$ ganglion extradurally, either just medial or dorsal to the lateral mass of $\mathrm{C} 1$, and the $\mathrm{C} 1-\mathrm{C} 2$ facet joint and medial to the vertical segment of the vertebral artery. Distal to the ganglion, the $\mathrm{C} 2$ nerve divided into a larger dorsal and a smaller ventral ramus. The ventral ramus passed behind the vertical segment of the vertebral artery and traversed forward and laterally. After supplying the inferior oblique muscle, the dorsal ramus was noticed to divide into a small lateral and a large medial division. The medial division continues as GON. The lateral branch was dissected only leaving the posterior interspace. The GON was observed to climb between semispinalis capitis and trapezius muscle and exiting lateral to the inion to innervate the skin up to vertex. Special attention was focused on observing the relative position of the $\mathrm{C} 2$ ganglion with respect to the lateral mass of the $\mathrm{C} 1$ vertebra. Interestingly, in all specimens it was noticed that the ganglion rests right behind the lateral mass of $\mathrm{C} 1$ vertebra and significantly hinders the safe deployment of $\mathrm{C} 1$ lateral mass screws. 


\section{Discussion}

In this study, we delineated the anatomical borders in the posterior aspect of the atlantoaxial region and identified the location of both the $\mathrm{C} 2$ nerve root and its ganglion in relation to the surrounding structures. We recognized that the nerve hindered the proper placement of C1 lateral mass screws and access to C1-C2 facet joints for decortication and/or placement of cages. This may contribute to post-operative complications such as occipital neuralgia and suboptimal fusion.

Although not considered as a true objective measure of functional outcome, some patients have complained of postoperative occipital numbness [6]. Fortunately, these patients are often times never uncomfortable enough to call it a true neuropathic pain. Aryan, et al. followed 102 patients who had C2 neurectomies as part of posterior C1-2 instrumented fusions. Only one patient complained of neuropathic pain in the sensory distribution without any reports of hypesthesia [7]. Another study found similar results in 20 patients with none of the patients developing a true neuropathic pain postoperatively, only five patients developing occipital anesthesia and another five developing hypesthesia. Only one patient with sensory disturbance reported a negative effect on health-related quality of life (HRQOL) due to daily occurrence [8]. All other patients reported much less frequent occurrences at weekly and monthly intervals. Dewan, et al. prospectively followed 28 patients who underwent atlantoaxial fusion with or without C2 neurectomy (eight transections, 20 preservations), and found that while $50 \%$ of patients who underwent transection complained of occipital numbness, none reported a negative effect on HRQOL. On the other hand, 35\% of patients who had their C2 nerves preserved complained of occipital neuralgia with all of them reporting the symptom to be bothersome and having significant effect on HRQOL [9]. Similar results were observed in other studies where patients reported relief of preoperative neck pain or radicular pain at the expense of minimal numbness in the C2 distribution with excellent results in fusion $[6-7,10,12]$

Not all literature is in agreement with the relative benign prognosis of undergoing a C2 neurectomy. Yeom, et al. compared 24 patients who had bilateral C2 transections with 41 patients without neurectomies. Patients who had neurectomies were found to have a greater percentage in incidences of postoperative neuralgic pain. Interestingly, they also found that the intensity of pain was much greater postoperatively in the patients who underwent transections. However, it should be noted that in their cohort, the ganglion was not completely dissected prior to transection which leads to the nerve root being transected through the ganglion itself rather than proximal to it [13]. Transection proximal to the ganglion is preferred as the cell bodies, are located within the ganglion and may be a cause of occipital pain if, damaged or compressed [14]. Isolated C2 nerve root pain is usually not treated with C2 neurectomy, as management is focused on treating the primary cause of pain. However, patients with C2 nerve root pain resulting from aberrant nerve root regeneration subsequent to incomplete destruction of the dorsal root ganglion respond well to C2 neurectomy and/or ganglionectomy [15-16].

A meta-analysis performed by Elliot, et al. found not only improved rates of occipital neuralgia in patients after $\mathrm{C} 1-\mathrm{C} 2$ fixation with $\mathrm{C} 2$ neurectomies, but also found that sacrifice of $\mathrm{C} 2$ was associated with reduced estimated blood loss (EBL), estimated operative time, and neuropathic pain. Also, there was no effect on the rates of fusion [17]. Similar results were found in other studies $[9,11]$. From our experience, a meticulous subperiosteal dissection (rostral to caudal) of the $\mathrm{C} 1-\mathrm{C} 2$ joint is a crucial step in posterior instrumentation. Coagulation of the venous plexus around the $\mathrm{C} 2$ nerve root proves important for the complete visualization of the $\mathrm{C} 1$ lateral masses and deployment of screws $[8,16,18]$. The C2 nerve, due to its positioning relative to the C1 lateral masses, often necessitates increased operative time in order to dissect out the surrounding structures, which can lead to increased EBL. Furthermore, C2 neurectomies can aid in visualization and feasibility in cases of $\mathrm{C} 1$ posterior arch nonunion or fractures as well as avoid cardiovascular instability in bleeding diathesis, aid in anterolateral access to the cervical 
segment of the spinal cord, and optimize decortication of the C1-C2 facet joint for successful fusion [17].

Wide exposure of the lateral mass of $\mathrm{C} 1$ can also be obtained by drilling the inferior half of the $\mathrm{C} 1$ lamina off to avoid unnecessary pressure on the $\mathrm{C} 2$ nerve root and ganglion. This step can help preserve the C2 nerve root but places the vertebral artery in jeopardy instead [1,8,18-19]. In another meta-analysis, it was found that atlantoaxial fusions accompanied by $\mathrm{C} 2$ transections were less likely to lead to vertebral artery injury as compared to $\mathrm{C} 2$ preservation. Furthermore, the incidences of both clinically significant and radiographic screw malpositions were much less frequent when the $\mathrm{C} 2$ nerve was sacrificed. Similar to previous reports mentioned, the incidence of postoperative occipital numbness was much higher in patients who had neurectomies but the rate of neuralgia was much less [20].

Through our cadaveric dissections, we highlighted the close proximity of neurovascular structures in the confined posterior C1-C2 interspace. We also highlighted that the $\mathrm{C} 2$ nerve is superficial, fixed in position, traverses a confined space and is also in close proximity to the C1C2 facet joint, which predisposes it to compression or neuropathy in subluxation and facet arthropathies. Although the bony anatomy is fairly consistent, the relative diameter and position (measurements not performed) of the $\mathrm{C} 2$ nerve, the length of the preganglionic segment, postganglionic segment, the diameter of the $\mathrm{C} 2$ ganglion, and its position relative to the $\mathrm{C} 1-\mathrm{C} 2$ facet joint were the important parameters. Many spine surgeons advocate for complete excision of the $\mathrm{C} 2$ nerve root plus ganglion but care has to be taken to avoid excising the ganglion too proximal from the dural ring to avoid intractable postoperative cerebrospinal fluid (CSF) leak [10,14]. C2 neurotomy and/or ganglionectomy should be a safe and watertight procedure. Double ligation of the stump is a less favourable option to prevent the efflux of CSF postoperatively [21]. Apart from hypoesthesia and CSF leakage, there have also been reports of alopecia from denervation after transection of the $\mathrm{C} 2$ nerve [14].

In our specimens, we recommend the benefit of transection of the $\mathrm{C} 2$ nerve root in order to identify clear bony landmarks for easy C1 screw deployment and decortication for optimal fusion. As no two patients are identical, a spine surgeon must have a full appreciation of each patient's anatomy. Understanding of the anatomy of the C1-C2 region allows for safe deployment of instrumentation with minimal risk of cortical breakage or injury to the neurovascular structures. While there are guidelines for the proper placement of posterior C1C2 pars screws, adherence to such algorithmic details is limited when taking into account individual anatomic variations. Preserving the nerve root in an attempt to maintain neural integrity can jeopardize patient outcomes due to the complaints of postoperative occipital neuralgia.

There are limitations to this study that are appreciated. The sample size of specimens was limited. Furthermore, cadaveric specimens may not fully represent what is seen on the operating table.

\section{Conclusions}

The knowledge and understanding of the intricate microsurgical anatomy of the $\mathrm{C} 2$ nerve root are essential for proper placement of $\mathrm{C} 1$ lateral mass screws. The course of $\mathrm{C} 2$ nerve around the facet joint necessitates its removal in procedures requiring $\mathrm{C} 1$ lateral mass screw insertion. C2 neurectomy offers a reasonably safe dissection zone to avoid inadvertent vertebral artery injury while facilitating access to the $\mathrm{C} 1-\mathrm{C} 2$ joint for preparation, cage placement, and fusion.

While occipital numbness may develop, the more severe complication of postoperative occipital neuralgia is avoided. 


\section{Additional Information \\ Disclosures}

Human subjects: All authors have confirmed that this study did not involve human participants or tissue. Animal subjects: All authors have confirmed that this study did not involve animal subjects or tissue. Conflicts of interest: In compliance with the ICMJE uniform disclosure form, all authors declare the following: Payment/services info: All authors have declared that no financial support was received from any organization for the submitted work. Financial relationships: All authors have declared that they have no financial relationships at present or within the previous three years with any organizations that might have an interest in the submitted work. Other relationships: All authors have declared that there are no other relationships or activities that could appear to have influenced the submitted work.

\section{References}

1. Goel A, Shah A, Gupta: Craniovertebral instability due to degenerative osteoarthritis of the atlantoaxial joints: analysis of the management of 108 cases. J Neurosurg. 2010, 12(6):592601. 10.3171/2009.12.SPINE0999

2. Harms J, Melcher RP: Posterior C1-C2 fusion with polyaxial screw and rod fixation . Spine (Phila Pa 1976). 2001, 26(22):2467-2471.

3. Conroy E, Laing A, Kenneally R, Poynton: C1 lateral mass screw-induced occipital neuralgia: a report of two cases. Eur Spine J. 2010, 19(3):474-476. 10.1007/s00586-009-1178-3

4. Rhee W-T, You S-H, Kim S-K, Lee S-Y: Troublesome occipital neuralgia developed by c1-c2 harms construct. J Korean Neurosurg Soc. 2008, 43(2):111-113.

doi:10.3340/jkns.2008.43.2.111

5. Stulik J, Vyskocil T, Sebesta P, Kryl J: Atlantoaxial fixation using the polyaxial screw-rod system. Eur Spine J. 2007, 16(4):479-484. 10.1007/s00586-006-0241-6

6. Goel A: Atlantoaxial fixation using plate and screw method: a report of 160 treated patients . Neurosurgery. 2002, 51(6):1351-1357.

7. Aryan HE, Newman CB, Nottmeier EW, Acosta FL, Wang VY, Ames: Stabilization of the atlantoaxial complex via C-1 lateral mass and C-2 pedicle screw fixation in a multicenter clinical experience in 102 patients: modification of the harms and goel techniques. J Neurosurg. 2008, 8(3):222-229. doi:10.3171/SPI/2008/8/3/222

8. Kang MM, Anderer EG, Elliott RE, Kalhorn SP, Frempong-Boadu: C2 nerve root sectioning in posterior C1-2 instrumented fusions. World Neurosurg.. 2012, 78(1-2):170-177. doi:10.1016/j.wneu.2011.07.010

9. Dewan MC, Godil SS, Mendenhall SK, Devin CJ, McGirt MJ: C2 nerve root transection during C1 lateral mass screw fixation: does it affect functionality and quality of life?. Neurosurgery. 2014, 74(5):2014-74. doi:10.1227/NEU.0000000000000306

10. Squires J, Molinari: C1 lateral mass screw placement with intentional sacrifice of the C2 ganglion: functional outcomes and morbidity in elderly patients. Eur Spine J. 2010, 19(8):1318-1324. 10.1007/s00586-010-1452-4

11. Hamilton DK, Smith JS, Sansur CA, Dumont AS, Shaffrey: C-2 neurectomy during atlantoaxial instrumented fusion in the elderly: patient satisfaction and surgical outcome. J Neurosurg. 2011 , 15(1):3-8. doi:10.3171/2011.1.SPINE10417

12. Patel AJ, Gressot L V., Boatey J, Hwang SW, Brayton A, Jea: Routine sectioning of the C2 nerve root and ganglion for C1 lateral mass screw placement in children: surgical and functional outcomes. Childs Nerv Syst. 2013, 29(1):93-97. 10.1007/s00381-012-1899-1

13. Yeom JS, Buchowski JM, Kim HJ, Chang BS, Lee CK, Riew KD: Postoperative occipital neuralgia with and without $\mathrm{C} 2$ nerve root transection during atlantoaxial screw fixation: a post-hoc comparative outcome study of prospectively collected data. Spine J. 2013, 13(7):786795. doi:10.1016/j.spinee.2013.04.006

14. Herzog JP, Groff MW: Does sacrifice of the C2 root benefit C1-2 arthrodesis? . World Neurosurg. 2012, 78(6):598-600. 10.1016/j.wneu.2012.01.022

15. Wang MY, Levi ADO: Ganglionectomy of C-2 for the treatment of medically refractory occipital neuralgia. Neurosurg Focus. 2002, 12(1):1-3 . 10.3171/foc.2002.12.1.15 


\section{Cureus}

16. Lozano AM, Vanderlinden G, Bachoo R, Rothbart P: C-2 ganglionectomy for chronic intractable occipital pain. J Neurosurg. 1998, 89(3):359-365. 10.3171/jns.1998.89.3.0359

17. Elliott RE, Kang MM, Smith ML, Frempong-Boadu: C2 nerve root sectioning in posterior atlantoaxial instrumented fusions: a structured review of literature. World Neurosurg. 2012, 78(6):697-708. 10.1016/j.wneu.2011.10.035

18. Poletti CE, Sweet: Entrapment of the C2 root and ganglion by the atlanto-epistrophic ligament: clinical syndrome and surgical anatomy. Neurosurgery. 1990, 27(2):288-291.

19. Stechison MT, Mullin: Surgical treatment of greater occipital neuralgia: an appraisal of strategies. Acta Neurochir. 1994, 131(3):236-240. 10.1007/BF01808620

20. Elliott RE, Tanweer O, Frempong-Boadu A, Smith: Impact of starting point and C2 nerve status on the safety and accuracy of $\mathrm{C} 1$ lateral mass screws: meta-analysis and review of the literature. J Spinal Disord Tech. 2015, 28(5):171-85. 10.1097/BSD.0b013e3182898aa9

21. Traynelis VC: C-2 neurectomy. J Neurosurg Spine. 2011, 15(1):3-8. 